\title{
Comparison of two simulators to investigate thermal-hydraulic-mechanical processes related to nuclear waste isolation in saliferous formations
}

Laura Blanco Martín ${ }^{* a}$, Ralf Wolters ${ }^{\mathrm{b}}$, Jonny Rutqvist ${ }^{\mathrm{a}}$, Karl-Heinz Lux ${ }^{\mathrm{b}}$, Jens T. Birkholzer ${ }^{\mathrm{a}}$

${ }^{a}$ Earth Sciences Division, Lawrence Berkeley National Laboratory (LBNL), 1 Cyclotron Rd, MS

74R316C, Berkeley, CA 94720, USA

${ }^{b}$ Chair in Waste Disposal and Geomechanics, Clausthal University of Technology (TU Clausthal),

Erzstr. 20, Clausthal-Zellerfeld, 38678, Germany

${ }^{*}$ Corresponding author. Tel.: +15104865456 ; fax: +15104865686

E-mail addresses: 1blancomartin@lbl.gov, ralf.wolters@tu-clausthal.de, jrutqvist@1bl.gov, karlheinz.lux@tu-clausthal.de, jtbirkholzer@lbl.gov 


\begin{abstract}
We investigate the capabilities of two simulators, TOUGH-FLAC and FLAC-TOUGH, to predict the long-term thermal-hydraulic-mechanical response of a generic salt repository for high-level nuclear waste. These simulators are based on sequential coupling and include state-of-the-art knowledge for saliferous materials. Their main difference is the sequential method used. We present a benchmark between LBNL and TU Clausthal. The scenario studied assumes heat and gas generation from the waste packages, and crushed salt backfill. The comparison of results is very satisfactory, providing increased reliability and confidence in the capabilities of the simulators to evaluate the geological and engineered barriers in the long-term.
\end{abstract}

\title{
Keywords
}

Sequential modeling, coupled processes, benchmark, high-level nuclear waste, rock salt, crushed salt 


\section{Introduction}

The underground disposal of nuclear waste requires the analysis of complex interactions between physical and chemical processes [1-6]. To comply with safety requirements, the performance of a nuclear waste repository has to be evaluated in the long-term (typically, thousands or even millions of years for highlevel nuclear waste). Due to the complexity of the processes that need to be investigated, their interactions and the time scales considered, numerical modeling using proper tools and state-of-the-art knowledge is required [7].

Numerical modeling of coupled thermal-hydraulic-mechanical (and chemical) processes has been a frequent approach in recent years to tackle a wide variety of geosciences problems, including not only nuclear waste disposal, but also geological carbon sequestration, geothermal reservoir engineering and reservoir geomechanics [8-13]. Fully coupled and sequential approaches have been developed, implemented and improved as both computational capabilities and understanding of the involved processes have moved forward. Kim [14] and Olivella et al. [9] present extended descriptions of different formulations for coupled geomechanics and multiphase and heat flows. Fully coupled approaches are characterized by the simultaneous resolution of the governing equations of flow and geomechanics at each time step $[9,15,16]$. On the other hand, in sequential methods the flow and geomechanics subproblems are solved one by one, using the intermediate solution information technique [17]. Different coupling strengths are possible when using sequential approaches, depending on how often the coupling between the two sub-problems is performed (i.e., at every iteration, at every time step or after a given number of time steps). The main advantages of sequential methods include the use of existing robust and well-established simulators for each sub-problem, the resolution of smaller systems of equations, the use of different time-stepping algorithms and the possibility to study different domains in each subproblem [18-21]. When the sequential procedure is iterated at each time step until the solution converges, results from fully coupled and sequential schemes are the same [14]. However, while fully coupled approaches are unconditionally stable, stability and convergence are the key issues for the good 
performance of sequential schemes. In this respect, the fixed-stress split and the undrained split sequential methods are known to have favourable stability, consistency, accuracy and efficiency properties. In this research, we focus on sequential approaches to model coupled flow and geomechanics processes (i.e., thermal-hydraulic-mechanical, or THM) related to the underground disposal of high-level nuclear waste in saliferous formations. Although salt rock mass in principle does not have any connected pathways under undisturbed conditions and therefore is regarded as liquid and gas tight [2,6,22-24], the analysis of fluid dynamic processes in an abandoned repository (in particular, two-phase flow induced and affected by heat and gas generation from the high-level nuclear waste packages, and also by the timedependent convergence of the emplacement drifts) is of particular importance when investigating the long-term integrity (i.e., tightness or sufficient low permeability) of the geological and engineered barriers. Therefore, the development, verification and validation of suitable simulators are required for the analysis of THM coupled processes in a high-level nuclear waste repository in salt rock mass. In this research, we use two different sequential simulators, based on the same flow and geomechanics software, but relying on two different numerical schemes. The TOUGH-FLAC simulator has been developed at Lawrence Berkeley National Laboratory [11] and is based on a fixed-stress split method. The FLACTOUGH simulator, developed at Clausthal University of Technology [25], is based on an undrained split method. As their names suggest, both simulators use TOUGH2 for the non-isothermal, multicomponent and multiphase flow sub-problem [26], and $\mathrm{FLAC}^{3 \mathrm{D}}$ to solve the geomechanics sub-problem [27]. Since state-of-the-art constitutive relationships and coupling functions can be implemented with ease into these two simulators, they can be applied not only to model THM coupled processes in saliferous materials, but also to investigate a wide range of geosciences topics. One innovation of the updated simulators presented in this paper is that they use a Voronoi discretization in the flow sub-problem, even when the mesh deforms over time due to the creep and the large strains associated with the mechanical behavior of saliferous materials. We present results of a benchmark exercise between Lawrence Berkeley National Laboratory and Clausthal University of Technology. The principal objectives of this benchmark are to 
model the same scenario using the two mentioned simulators and to compare the results obtained. Indeed, it is acknowledged that, besides the validation of physical processes, the comparison of numerical results issued from different approaches and institutions increases confidence and reliability on the long-term predictions, and enhances acceptance of the conclusions reached [28]. In addition, such comparison leads to a code-to-code verification. Several benchmark projects to compare constitutive models for the thermal-mechanical behavior of rock salt have been reported in the literature [28-33]. Here, we focus on (1) the backfill evolution (in particular, reconsolidation process), on (2) processes that could affect the integrity of the host rock natural barrier at different temporal and spatial scales (i.e., temperature changes, damage, dilatancy and healing/sealing), and on (3) the effect of gas generation from the waste packages on the barriers integrity. We compare and analyze the capabilities of TOUGH-FLAC and FLAC-TOUGH to model the long-term coupled THM response of a repository for high-level nuclear waste in rock salt. Rock salt is a potential medium for the underground disposal of nuclear waste because of several assets, including its water and gas tightness in the undisturbed state, its ability to creep and heal technically induced fractures and its relatively high thermal conductivity as compared to other shallow-crustal rock types $[1,2,29,34,35]$. In addition, rock salt is easy to mine, requires little reinforcement and can be found underground in large volumes in stable geological areas [28]. Furthermore, worldwide experience from the salt mining industry is available and includes construction know-how, long-term behavior of underground excavations in saliferous geosystems, geotectonic inventory of these geosystems and modes of failure mechanisms. With the aim of performing generic research that will support future site-specific work [36], we have considered a generic salt repository for high-level nuclear waste. Our repository assumes in-drift emplacement of the waste packages and subsequent backfill of the drifts with run-ofmine, granular salt. In this scenario, as the natural salt creeps under the effect of temperature and deviatoric stresses, the crushed salt backfill, which initially had a porosity of 30-45\%, undergoes a reconsolidation process. It is expected that, when compacted, the crushed salt backfill will provide an additional (engineered) barrier role, thereby contributing to the natural barrier supplied by the host 
rock [37]. Indeed, during the reconsolidation process, the flow and mechanical properties of the crushed salt evolve towards the characteristic values of the natural salt $[29,37,38]$. As it will be discussed later, the evolution of some of these properties is currently well understood; however, the reconsolidation process at the high temperatures associated with heat-generating nuclear waste, as well as the effect of the moisture content on the compaction rate are currently under investigation [34,39]. Moreover, there are still some uncertainties about the remaining permeability and porosity of highly compacted crushed salt, as only a few experimental results are available [40].

This paper is organized as follows. First, we present the two sequential simulators used, TOUGH-FLAC and FLAC-TOUGH. Then, we present the new procedure to update the mesh in the flow simulation as the mechanical mesh deforms. The coupling between flow and geomechanics, including material-specific coupling functions for the crushed salt and the natural salt, is explained as well. The coupling functions that we use are based on current knowledge about the behavior of salt rock mass and granular salt under repository conditions for high-level nuclear waste, and will be improved as more data become available. Later, we give details on the benchmark exercise, and we compare and discuss the predictions obtained by the two simulators for the generic salt repository considered. The simulations include the stages of excavation, waste emplacement, backfilling and 100000 years of post-closure. The comparison is very satisfactory, leads to a code-to-code verification, and demonstrates and provides confidence in the capabilities of the sequential approaches and simulators used to predict the long-term coupled THM response of a generic salt repository for high-level nuclear waste.

\section{Materials and Methods}

The two simulators used in this research, TOUGH-FLAC and FLAC-TOUGH, present several similarities: (1) they are based on the same software (TOUGH2 and FLAC ${ }^{3 \mathrm{D}}$ ), (2) they are both sequential simulators (i.e., the flow and geomechanics sub-problems are solved sequentially), (3) they can deal with large deformations, creep processes, non-isothermal, multiphase and multicomponent (at least, water and 
air) flow, and (4) they offer advanced constitutive relationships to model the time-dependent response of salt rock mass and granular salt. The main difference between these simulators is that they use two different methods to sequentially solve the flow and geomechanics sub-problems, as will be explained below.

\subsection{TOUGH-FLAC for large strain and creep processes}

The TOUGH-FLAC simulator [11] has been successfully used in many geosciences fields, and for the analysis of a wide range of geoengineering problems [10,11]. In order to investigate large strains and creep processes, TOUGH-FLAC has recently been updated [41]. One important update deals with the adaptation of the flow simulator (TOUGH2) to large deformations; this has required some modifications in the mass and energy balance equations (to ensure mass and heat conservation as geometry changes), and also the update of relevant geometrical data (note that FLAC $^{3 \mathrm{D}}$ has a capability for large strains). TOUGH-FLAC is based on the fixed-stress split sequential method to couple flow and geomechanics [42]. Accordingly, the flow sub-problem is solved first in the sequential scheme, using an explicit evaluation of the volumetric component of the total stress tensor. We note that TOUGH2 is the master code of the simulator and that it moves the simulation forward in time, once convergence has been reached in each time step. Fig. 1 shows a schematic view of the modeling sequence used in TOUGHFLAC. The highlighted area corresponds to a time step from $t^{n}$ to $t^{n+1}$. During the geomechanics subproblem, the pore pressure, $P$, and temperature, $T$, that were computed by TOUGH2 remain constant (drained conditions), but every time the coupling is made, the total stress tensor ( $\sigma^{n-1}$ in Fig. 1$)$ is updated to account for pore pressure and temperature changes that occur between two successive calls to FLAC ${ }^{3 \mathrm{D}}$. This yields a corrected tensor, $\sigma^{n-1, \text { corr }}$ (more details will be given in section 2.4). To ensure consistency of the quasi-static governing equations, liquid saturation, $S_{l}$, and porosity, $\phi$, are also updated in the geomechanics sub-problem (for the computation of the body forces).

The mechanical equilibrium state obtained at the end of every FLAC ${ }^{3 \mathrm{D}}$ run (stresses $\sigma^{n}$ and strains $\varepsilon^{n}$ in Fig. 1) is used to compute changes in flow parameters, such as porosity, permeability, $k$, and capillary 
pressure, $P_{c}$, through several coupling functions. The coupling functions used in the current research are common to the two simulators presented in this paper and will be described in section 2.4. In addition, if large strains occur during the geomechanics sub-problem, the geometrical data and the balance equations are updated in TOUGH2.

Finally, we note that the transfer of information between the two software is made through intermediate files, because the source code of $\mathrm{FLAC}^{3 \mathrm{D}}$ is not available.

\subsection{FLAC-TOUGH for large strain and creep processes}

In contrast with the TOUGH-FLAC simulator, which is based on the fixed-stress split method, the FLACTOUGH simulator has been originally implemented based on the undrained split method, but at present two different sequential methods are available. In both methods, the geomechanics code FLAC ${ }^{3 \mathrm{D}}$ is the master code and sequentially (e.g. after each 1000 mechanical creep iteration steps) calls the flow code TOUGH2 as a slave code. Fig. 2 shows the sequential algorithm used in FLAC-TOUGH as a schematic view. The difference between the two sequential methods which are implemented in FLAC-TOUGH is as follows. In the first approach, the FLAC-TOUGH simulator is based on the sequential undrained split method [14]. The geomechanical deformations as well as the resulting changes in stress, pore volume and pore pressure conditions for each element are computed first by $\mathrm{FLAC}^{3 \mathrm{D}}$ in each iteration step of the mechanical simulation part, while fluid masses and temperature are kept constant for each element. At the end of a mechanical simulation part, the resulting pore pressure and saturation values as well as values concerning porosity and permeability (see section 2.4 ) are written into certain files, which are read by TOUGH2 after calling it as a slave code to compute the multiphase mass and heat flows. Changes in pore pressure, saturation and temperature resulting from multiphase mass flow or heat flow are transferred to FLAC $^{3 \mathrm{D}}$ via writing them to certain files again after finishing the TOUGH2-call. The coupling scheme based on the undrained-split method is very computational cost intensive because the necessary FISHfunctions in $\mathrm{FLAC}^{3 \mathrm{D}}$ used for updating pore pressures are not parallelized, and called in every FLAC ${ }^{3 \mathrm{D}}$ iteration step. To reduce the amount of FISH-functions calls, in a second approach the FLAC-TOUGH 
simulator is implemented in a way such that the pore pressure is kept constant during the mechanical simulation part, but updated with the overall deformation increment occurring between two consecutive TOUGH2-calls at the end of the mechanical simulation part; therefore, this second approach may be seen as a mixture of the undrained-split and the drained-split methods [14]. The numerical results shown in this paper are obtained using the faster second coupling scheme approach.

\subsection{Mesh update in the flow simulation}

The use of TOUGH2 to model flow in porous media that experience large deformations requires that the geometrical data used in this simulator be updated (total Lagrangian method). Among others, large deformations may be related to compaction (i.e., pore volume reduction) and creep processes. One advantage of using a sequential approach to solve coupled THM processes is that a different grid may be used in each sub-problem. In general, the optimal discretization of the flow and geomechanics problems is not the same [43]. Moreover, the resolution method used in TOUGH2 is based on the Voronoi partition [26]; therefore, more accurate solutions will be obtained when the discretization of the flow sub-problem conforms to this technique.

If the domain under study deforms over time, the partition used in the flow sub-problem should still comply with the resolution method of the code. Bearing this in mind, we use the software library Voro++ [44] to ensure that the mesh used in TOUGH2 conforms to the principles of the Voronoi tessellation. This is an innovation with respect to previous studies using TOUGH-FLAC and FLACTOUGH.

As the mesh deforms in the geomechanics sub-problem, Voro++ is executed to compute the corresponding Voronoi tessellation. This operation is performed every time maximum local strains exceed a preset value, typically 2-5\% [45]. In the current approach, the centroids of the deformed geomechanics mesh are transferred to Voro++, which computes the corresponding Voronoi discretization. Geometrical data of the new Voronoi mesh (volumes, common interface area between two adjacent grid blocks, etc.) are then transferred to TOUGH2. 
Fig. 3 shows a detail of the two grids used in the THM simulations presented in this paper (initial mesh and deformed mesh after 20 years). As it can be seen, the flow sub-problem uses Voronoi cells, both in the initial and the deformed configurations. In addition, it can be seen in the figure that the grid blocks at the boundary between two different domains (waste package, backfill and host rock) are slim and have the same thickness. This way, Voro++ will conserve the volume of each domain even when the mesh deforms (the generators of the Voronoi mesh are the centroids of the mesh used in FLAC $^{3 \mathrm{D}}$ ).

\subsection{Coupling between flow and geomechanics}

From flow to geomechanics, the total stress tensor, $\sigma_{i j}[\mathrm{MPa}]$, is corrected to account for fluid pressure changes, $\Delta P[\mathrm{MPa}]$, and temperature changes, $\Delta T[\mathrm{~K}]$, between two consecutive calls to FLAC ${ }^{3 \mathrm{D}}$. These changes are computed from TOUGH2 results, and calculated internally in $\mathrm{FLAC}^{3 \mathrm{D}}$ once the new values of fluid pressure and temperature are transferred from TOUGH2. The corrected tensor, $\sigma_{i j}^{\text {corr }}[\mathrm{MPa}]$, reads

$$
\sigma_{i j}^{c o r r}=\sigma_{i j}-\alpha \Delta P \delta_{i j}-3 \alpha_{T} K \Delta T \delta_{i j}
$$

where $\alpha[-]$ is the Biot coefficient of the material, $\alpha_{T}\left[\mathrm{~K}^{-1}\right]$ is its linear thermal expansion coefficient, $K[\mathrm{MPa}]$ is its bulk modulus and $\delta_{i j}[-]$ is the Kronecker delta. Here, we consider that compressive stresses are negative. From Eq. (1), it can be inferred that the flow only affects the volumetric component of the stress tensor.

It is often admitted that the Biot coefficient of undisturbed rock salt is very close to zero [46]. Experimental evidence $[46,47]$ suggests that damage processes increase the Biot coefficient of rock salt according to

$$
\alpha_{\text {salt }}=\max \left(\frac{D}{D_{\alpha}}, 1-\exp \left(\frac{\sigma_{v} m D}{D-D_{\alpha}}\right)\right)
$$

where $\alpha_{\text {salt }}[-]$ is the current Biot coefficient of the rock salt mass, $D[-]$ is a damage parameter $[6,46]$, $D_{\alpha}=0.1[-]$ is a constant, $\sigma_{V} \geq 0[\mathrm{MPa}]$ is von Mises equivalent stress and $m<0\left[\mathrm{MPa}^{-1}\right]$ is a parameter that enhances Maxwell viscosity (Maxwell viscosity is a parameter in rheological viscoplastic models and 
decreases if either temperature or equivalent stress increases. Here, parameter $m$ determines the influence of the equivalent stress on Maxwell viscosity, cf. [1,6]). As Eq. (2) suggests, the coupling strength between the geomechanics and flow sub-problems depends on the damage evolution. In addition, we note that healing reduces damage, and therefore can restore the initial Biot coefficient of the rock salt. As for the granular salt, the Biot coefficient decreases during compaction, from almost 1 when the bulk modulus is low, to the characteristic value of the undisturbed natural salt as the bulk modulus increases. The classic definition is used in this case [48]. It reads

$$
\alpha_{\text {crushed salt }}=1-\frac{K}{K_{s}}
$$

where $\alpha_{\text {crushed salt }}[-]$ is the current Biot coefficient of the granular salt, $K[\mathrm{MPa}]$ is the drained bulk modulus and $K_{s}[\mathrm{MPa}]$ is the bulk modulus of the solid material.

From geomechanics to flow, several coupling functions are used to compute mechanically induced changes in flow properties. In this study, we focus on changes to porosity and permeability, both in the host rock and the backfill. The coupling functions used are material-specific and are based on laboratory and theoretical results.

For the natural salt, the evolution of porosity is based on the evolution of dilatancy. Dilatancy is nonelastic volumetric strain. The expression used reads

$\phi_{\text {salt }}=\phi_{0}+\varepsilon_{\text {vol }}$

where $\phi_{\text {salt }}[-]$ is the current salt porosity (secondary porosity), $\phi_{0}[-]$ is the porosity of the undisturbed salt (primary porosity), and $\varepsilon_{v o l} \geq 0$ [-] is dilatancy. We note that Eq. (4) is a simplified expression to compute the evolution of porosity. We intend to extend this formulation to fully account for poromechanical coupling. Regarding permeability, several laboratory investigations have shown that the initial tightness of rock salt may be superseded by a secondary permeability if damage occurs [6,49-52]. Thermo-mechanically 
induced damage takes places if the dilatancy boundary is exceeded. In this case, the evolution of the secondary permeability can be modeled using

$$
k_{\text {salt }}^{\text {secondary }}=10^{\log \left(k_{\text {min }}^{\text {secondary }}\right)+\left\langle\log \left(\varepsilon_{\text {vol }}\right)-\log \left(\varepsilon_{\text {vol }, 0}\right)+d \exp \left(f \sigma_{\perp 2}^{\prime}\right) \frac{1}{\ln (10)}\left(\operatorname{Ei}\left(e \varepsilon_{\text {vol }}\right)-\operatorname{Ei}\left(e \varepsilon_{\text {vol }, 0}\right)\right)\right\rangle} k^{*}
$$

with $\langle x\rangle=x$ if $x>0$ and $\langle x\rangle=0$ otherwise. Parameter $k_{\min }^{\text {secondary }}\left[\mathrm{m}^{2}\right]$ is the minimum secondary permeability at the onset of thermo-mechanically induced damage (about $10^{-22} \mathrm{~m}^{2}$ ), $\varepsilon_{v o l, 0}[-]$ is the dilatancy limit at which $k_{\min }^{\text {secondary }}$ starts to develop due to the connection of micro-fissures, $\sigma_{\perp 2}{ }^{\prime}[\mathrm{MPa}]$ is the effective stress perpendicular to the orientation of the micro-fissures, $\operatorname{Ei}(x)$ is the exponential integral function and $k^{*}=1 \mathrm{~m}^{2}$ (therefore, the secondary permeability is $k_{\text {salt }}^{\text {secondary }}\left[\mathrm{m}^{2}\right]$ ). Parameters $d, e$ and $f$ are salt-specific. Eq. (5) has been developed based on experimental evidence [6,53]. The permeability recovery due to healing (dilatancy decrease) can be also modeled using Eq. (5). Another damage process that may affect the initial tightness of rock salt is hydraulically induced damage. Hydraulically induced damage occurs if the pore pressure exceeds locally the minimum principal stress, without necessarily exceeding the dilatancy boundary $[6,23]$. An infiltration process is thereby triggered. If hydraulically induced damage occurs, the permeability evolution can be modeled using

$$
k_{\text {salt }}^{\text {secondary }}=10^{i_{1}+i_{2} \arctan \left(i_{3} \Delta P_{F l}\right)+i_{4} \exp \left(i_{5} \Delta P_{F l}\right)} k^{*}
$$

where $\Delta P_{F l}=\sigma_{3}+P[\mathrm{MPa}]$ ( $\sigma_{3}$ is the minimum compressive principal stress and $P$ is the pore pressure), parameters $i_{1}, i_{2}, i_{3}, i_{4}$ and $i_{5}$ are salt-specific [6], and $k^{*}=1 \mathrm{~m}^{2}$ (therefore, the secondary permeability is $\left.k_{\text {salt }}^{\text {secondary }}\left[\mathrm{m}^{2}\right]\right)$. We note that we use Eq. (6) if $\Delta P_{F l} \geq 0$. This is in agreement with previous research, which state that micro-fractures develop if $P \approx \sigma_{3}[54,55]$.

Regarding the crushed salt, the evolution of porosity during compaction is directly related to the evolution of density. Therefore, we use

$\phi_{\text {crushed salt }}=1-\rho / \rho_{g r}$ 
where $\phi_{\text {crushed salt }}[-]$ is the current porosity of the crushed salt, $\rho\left[\mathrm{kg} \cdot \mathrm{m}^{-3}\right]$ is the current drained density and $\rho_{g r}\left[\mathrm{~kg} \cdot \mathrm{m}^{-3}\right]$ is the density of the salt grains. During compaction, the permeability of the crushed salt decreases significantly. According to experimental data [37], in this research we use

$$
k_{\text {crushed salt }}=5.6810^{-11} \phi^{4.36}
$$

where $\phi[-]$ is the current crushed salt porosity and $k_{\text {crushed salt }}\left[\mathrm{m}^{2}\right]$ is the current crushed salt permeability. We note that Eq. (8) is based on porosity data in the range $1.5-40 \%$.

In addition to these mechanically induced changes in porosity and permeability, in this study we account for the increase in the thermal conductivity of the crushed salt during compaction. Results from experimental work $[29,37]$ suggest that the thermal conductivity-porosity relationship may be expressed

$$
\lambda_{\text {crushed salt }}=-270 \phi^{4}+370 \phi^{3}-136 \phi^{2}+1.5 \phi+5
$$

where $\phi[-]$ is the current crushed salt porosity and $\lambda_{\text {crushed salt }}\left[\mathrm{W} \cdot \mathrm{m}^{-1} \cdot \mathrm{K}^{-1}\right]$ is the current thermal conductivity of the crushed salt.

\section{Application: generic salt repository with crushed salt backfill and gas generation from high- level nuclear waste packages}

We now explore the capabilities of TOUGH-FLAC and FLAC-TOUGH to model the time-dependent coupled THM response of a generic salt repository for high-level nuclear waste. We model the same scenario with the two simulators and we analyze and compare the results obtained.

\subsection{Description of scenario}

In the scenario defined, a high-level nuclear waste repository is in the middle of a $400 \mathrm{~m}$ thick salt layer, at a depth of $600 \mathrm{~m}$. Two sandstone layers, each $400 \mathrm{~m}$ thick, confine the rock salt. Fig. 4 shows an overall view of the model and an enlarged view of the drift area. As explained in section 2.3, a Voronoi discretization is used in the flow sub-problem, so that the results are more accurate from a numerical point of view, the number of connections is increased and the results are less dependent on the mesh structure. 
The model extends $1200 \mathrm{~m}$ in the vertical direction ( $Z$ axis) and $25 \mathrm{~m}$ in the horizontal direction ( $X$ axis); the latter corresponds to a possible half distance between drifts. Due to symmetry reasons, only half of one drift is modeled. This drift is $3.5 \mathrm{~m}$ high and $4.5 \mathrm{~m}$ wide. The waste packages are emplaced parallel to the drift axis, have a diameter of $1.6 \mathrm{~m}$, are $5.5 \mathrm{~m}$ long and are $3 \mathrm{~m}$ apart. The remaining space of the drift is backfilled with crushed salt. Since the simulations are computationally demanding, we focus on a twodimensional case to enhance the comparison of the results obtained by the two simulators. Moreover, given the expected lengths of the drifts, we believe that a 2D simulation with a plane strain approximation is suitable in a first stage to capture heat flow, two-phase mass flow, damage and creep evolution, crushed salt consolidation, and the impact of gas generation on the long-term predictions.

The heat load released from the waste packages after underground emplacement, and scaled to our 2D model, is shown in Fig. 5. This heat load is consistent with the expected nuclear waste characteristics within the US Department of Energy Used Fuel Disposition Campaign [56]. It is assumed that each waste package contains ten pressurized water reactor (PWR) assemblies and that the packages are emplaced underground after 20 years of interim storage. In Fig. 5, the time has been reset to zero when the waste packages are emplaced underground.

Different phenomena have been studied in the benchmark exercise performed. Regarding the flow subproblem, we have investigated the fate of the heat flow, along with two-phase flow of water and air. Conductive and convective heat flows are possible, as well as advective and diffusive mass transport. TOUGH2 equation of state (EOS) 3 has been used. Diffusive mass transport of water and air is modeled with coefficients that depend on pressure and temperature, and tortuosity effects are accounted for using the Millington and Quirk model [26].

In order to account for possible corrosion of the waste packages over time, a gas generation rate has been included in the simulations. It has been estimated assuming a corrosion rate of $1 \mu \mathrm{m} \cdot \mathrm{y}^{-1}$. This rate is an average value of available corrosion data for steel nuclear waste packages [57]. From the chemical 
reactions describing corrosion, the amount of gas released per meter of drift and per unit of time has been determined to be $1.85 \cdot 10^{-12} \mathrm{~kg} \cdot \mathrm{s}^{-1} \cdot \mathrm{m}^{-1}$.

From a mechanical viewpoint, the time-dependent response of the natural salt is described using the Lux/Wolters constitutive model, which allows modeling elastic, visco-plastic, damage and healing processes characteristic of rock salt [1,6,58-62]. This state-of-the-art constitutive model has been validated against field and experimental data $[1,6]$. It has been implemented in FLAC $^{3 \mathrm{D}}$ as a user-defined model. For the crushed salt, we use a modified version of the cwipp model implemented in FLAC ${ }^{3 \mathrm{D}}$ [27]. The main characteristic of the cwipp model is that it allows modeling time-dependent volumetric strain changes. While density is not allowed to decrease in the cwipp model (i.e., density is a monotonically increasing function), it honors the volumetric strain evolution in our modified version. Regarding the waste package and the confining layers, their mechanical response is assumed to be elastic.

Table 1 lists relevant mechanical and flow parameters of the crushed salt, the natural salt and the confining layers. The parameters of the Lux/Wolters model have been determined from the interpretation of experimental results [63]. Those of the cwipp model have been adapted from available data $[27,64]$. For the waste package, standard properties of steel have been used in the flow and mechanical subproblems, with $\alpha=1, k=0 \mathrm{~m}^{2}$ and $\phi=0.01 \%$ (smaller than that of the host rock). We note that well-known dependence of flow properties on temperature have been considered, both for the natural salt and the crushed salt $[29,41]$. Specifically, the thermal conductivity of the natural salt decreases non-linearly with temperature, and the grain specific heat of both materials increases linearly with temperature. The following expressions have been used:

$\lambda_{\text {salt }}=5.734-1.838 \cdot 10^{-2} T+2.86 \cdot 10^{-5} T^{2}-1.51 \cdot 10^{-8} T^{3}$

for the thermal conductivity, $\lambda_{\text {salt }}\left[\mathrm{W} \cdot \mathrm{m}^{-1} \mathrm{~K}^{-1}\right]$ (with $T\left[{ }^{\circ} \mathrm{C}\right]$ ), and $C=855+0.177 T$

for the grain specific heat, $C\left[\mathrm{~J} \cdot \mathrm{kg}^{-1} \mathrm{~K}^{-1}\right]$ (with $T\left[{ }^{\circ} \mathrm{C}\right]$ ). 
The coupling functions between geomechanics and flow described in section 2.4 have been considered. For the confining layers and the waste package, we assume that the flow properties are not influenced by geomechanical effects (the waste package is only modeled to account for the heat and gas release into the repository and the confining layers are located far above and below the drift, so they are not significantly influenced by the THM processes occurring in the drift area). In the geomechanics sub-problem, the pore pressure used corresponds to the saturation-averaged sum of the phase pressures [48].

Initial flow parameters are listed in Table 2 . The absolute permeability $k$ is assumed isotropic for each material. Initial conditions are as follows. The mechanical condition is isotropic stress (due to the creep of the natural salt over geological time scales), equal to the lithostatic stress magnitude. For the calculation of the pore pressure, we assume that the water table is located at the ground surface. Regarding the fluid inclusions in the natural salt at the grain boundaries, we assume an initial liquid saturation of $50 \%$. A geothermal gradient of $0.025 \mathrm{~K} \cdot \mathrm{m}^{-1}$ is applied, which corresponds to about $28{ }^{\circ} \mathrm{C}$ at the repository level assuming a ground surface temperature of $10^{\circ} \mathrm{C}$.

In TOUGH2, Dirichlet boundary conditions are assigned to the top and bottom grid blocks, and the lateral surfaces of the model are no-flow boundaries. In $\mathrm{FLAC}^{3 \mathrm{D}}$, the horizontal displacement is blocked in planes $X=0$ and $X=25 \mathrm{~m}$, as well as the vertical displacement in plane $Z=-1200 \mathrm{~m}$. Gravitational effects are considered in both codes.

The following stages are modeled: initial equilibrium, drift excavation, emplacement of waste packages and backfilling, and 100000 years of post-closure. We assume that the pore pressure within the crushed salt and the waste package at emplacement is $0.1 \mathrm{MPa}$ (atmospheric pressure).

\subsection{Comparison of results}

In this benchmark exercise, our main goal is to compare numerical results obtained by the two simulators, concerning the different processes occurring in the salt rock mass as well as in the backfill material. We note that the discussion hereafter does not include yet a comprehensive validation based on measurement data of the physical processes. 
Fig. 6 compares the evolution of dilatancy (i.e., non-elastic volumetric strain) at the drift contour during the first years of the post-closure phase. We recall that the drift is backfilled since the beginning of this phase. As the figure shows, the predictions provided by the two simulators are very similar. In the first years, dilatancy increases and peaks at about $2.1 \%$ at the drift sidewall, after 4 years. The excavation damaged zone (EDZ) extends about $1.5 \mathrm{~m}$ below the drift floor and $1 \mathrm{~m}$ beyond the drift roof and sidewalls. According to Eq. (4), the secondary porosity of the host rock reaches $2.3 \%$ at the drift sidewall (see corresponding curve in Fig. 7). Due to damage, the Biot coefficient of the natural salt also increases (cf. Eq. (2)), thereby increasing the strength of the coupling between flow and geomechanics. A maximum value of 0.66 is predicted at the drift sidewall by the two simulators. In turn, the secondary permeability increases by several orders of magnitude according to Eq. (5).

Creep and dilatant behavior of the rock salt mass trigger the progressive compaction of the crushed salt. Crushed salt compaction is intensified by the increasing temperature in the rock salt mass, induced by the heat released from the high-level nuclear waste. As compaction moves forward, the crushed salt strengthens and an internal support is progressively developed in the rock salt mass at the drift contour. Healing mechanisms are activated, and dilatancy and damage decrease. As Fig. 6 shows, the EDZ is sealed after about 7 years. The initial tightness of the host rock is restored. In addition, the stress state progressively evolves to the initial isotropic state.

Fig. 7 displays the evolution of porosity at three locations in the crushed salt, during the first 20 years of post-closure. A location in the natural salt at the drift sidewall is also included in the plot. The evolution predicted by the two simulators is very similar. As the figure shows, porosity within the crushed salt is not uniform in space, due to the shape of the drift and the position of the waste package. Moreover, within the first 20 years of post-closure most of the crushed salt has reached the final porosity $(0.2 \%$, which is a characteristic value for the primary porosity of natural salt, see Table 2). The calculated time span for reconsolidation is comparable to previous numerical investigations [12]. It is important to highlight that, during reconsolidation, the hydraulic, thermal and mechanical properties of the crushed salt tend to those 
of the natural salt, as described in section 2.4 (Eqs. (3) and (7)-(9)), and also in [27]. In particular, a permeability reduction of up to nine orders of magnitude is predicted, as well as an increase in the thermal conductivity from about 1 to $4-5 \mathrm{~W} \cdot \mathrm{m}^{-1} \mathrm{~K}^{-1}$, and also an increase in the elastic moduli of two orders of magnitude and a reduction in the Biot coefficient from almost 1 to 0.003 . We recall that these predictions are based on available experimental data and their extrapolation for porosities smaller than $1.5 \%$.

The results obtained show that the crushed salt is characterized by a strong two-way interaction between flow (mass and heat) and geomechanics processes. Additionally, the time-dependent evolution of the host rock and the crushed salt is extremely interdependent: the natural salt triggers the crushed salt reconsolidation (through the closure of the drift), and this reconsolidation favors the onset of healing processes and the restoration of the initial natural salt barrier.

Fig. 8 displays the evolution of temperature at four different locations. Again, the predictions obtained by the two simulators are very similar. As the figure shows, the temperature at the waste package peaks slightly above $180{ }^{\circ} \mathrm{C}$ after about 1 year. The nearby crushed salt and natural salt also show an initial temperature peak; this local peak is due to the relatively low thermal conductivity of the crushed salt before significant compaction occurs. After about 20 years, the crushed salt is reconsolidated and the temperature evolution is uniform. In the near field, the temperature peaks at $162{ }^{\circ} \mathrm{C}$ after 25 years. Twenty-five meters away from the drift, the temperature reaches $100{ }^{\circ} \mathrm{C}$ before 100 years (progressive heat propagation through the host rock). It is important to highlight that the same heat release in argillaceous or crystalline rock environments would cause higher temperatures than the values mentioned, due to a lower thermal conductivity as compared to rock salt. After 100000 years, the initial temperature is restored. Cooling is slow enough to avoid tensile failure of the host rock. Note that as temperature evolves over time, the thermal conductivity of the natural salt, and the specific heat of the natural salt and the crushed salt, change according to Eqs. (10) and (11) respectively.

Fig. 9 displays the evolution of pore pressure in the drift area, as well as in a location $25 \mathrm{~m}$ away from the drift. In the drift area, a strong increase is predicted between 6 and 20 years as backfill porosity becomes 
very low (see Fig. 7). The pore pressure peaks at $19 \mathrm{MPa}$ as the porosity tends to $0.2 \%$ (natural salt initial porosity, see Table 2). Shortly after (about 45 years), the pore pressure stabilizes at 13.7 MPa (due to fluid infiltration into the rock salt mass and corresponding fluid pore pressure decrease), which is the value of the minimum principal stress in the drift area. This is in accordance with the infiltration criterion, which states that infiltration takes place if $\Delta P_{F l}=\sigma_{3}+P \geq 0$ (see Eq. (6)). If $P$ exceeds locally $\sigma_{3}$, a secondary permeability develops in the salt rock mass. Pore pressure cannot increase much above the infiltration criterion because infiltration will work against further increase of pore pressure, and it cannot decrease below the infiltration criterion because the infiltration-induced grain-boundary openings will close again and the salt rock mass will get impermeable as it was before, thereby triggering a new pore pressure increase. Finally, at the location $25 \mathrm{~m}$ away from the drift displayed in Fig. 9, the pore pressure starts increasing after 20000 years as the infiltration front propagates through the rock salt mass, although it does not reach the overlying sandstone layer, as explained below.

Fig. 10 compares the evolution of $\Delta P_{F l}$ predicted by the two simulators. The initial condition at the repository level is $\Delta P_{F l} \approx-8 \mathrm{MPa}$. Over time, because the pore pressure increases due to the crushed salt compaction, the thermal expansion of the fluids and the gas generation, $\Delta P_{F l}$ increases and may become positive, allowing for some infiltration to occur. In the long-term, the principal factor to the pore pressure increase is the gas generation, because the crushed salt is compacted within the first decades and temperature decreases (see Fig. 8). The zone in which infiltration could take place extends $67 \mathrm{~m}$ above the drift (the gas moves upwards), which is smaller than the rock salt thickness above the drift (200 m).

Fig. 11 displays the liquid saturation evolution at the same three locations as displayed in Fig. 9. Overall, the results of the two simulators are in good agreement. Far from the drift, saturation barely changes. In the crushed salt and rock salt at the drift contour, the liquid saturation increases steeply as reconsolidation takes place. In the crushed salt, the reduction of the pore volume explains the saturation increase. As for the natural salt, water is squeezed from the crushed salt during compaction. Note that in the first years, liquid saturation decreases in the drift area due to the temperature increase (vaporization). In the long- 
term, the liquid saturation in the drift area decreases and liquid water accumulates below the drift, as it flows by gravity (below the drift, some infiltration and secondary permeability develop, see Fig. 10).

\section{Discussion and Conclusions}

In this work, we compared the capabilities of two sequential numerical simulators, TOUGH-FLAC and FLAC-TOUGH, to predict phenomena occurring in the long-term in a generic salt repository for highlevel nuclear waste. TOUGH-FLAC has been developed at Lawrence Berkeley National Laboratory and FLAC-TOUGH has been developed at Clausthal University of Technology. These two simulators are based on sequential coupling of thermal-hydraulic and mechanical processes, and use the same software to solve the flow (TOUGH2 code) and geomechanics (FLAC ${ }^{3 \mathrm{D}}$ code) sub-problems. They both integrate state-of-the-art constitutive relationships for rock salt and granular salt, and also advanced coupling functions between geomechanics and flow, based on current knowledge about the behavior of salt rock mass and granular salt under repository conditions for high-level nuclear waste. The main difference between these two simulators is that they are based on two different methods to sequentially solve the flow and geomechanics sub-problems: TOUGH-FLAC is based on the fixed-stress split sequential method and FLAC-TOUGH is based on the undrained split sequential method. An important feature of the updated versions of the two simulators presented here is that they use a Voronoi discretization in the flow sub-problem, even when the mesh deforms over time due to the creep and the large strains associated with the mechanical behavior of saliferous materials.

We present results of a benchmark exercise performed between the two mentioned institutions. The same scenario has been modeled using the two sequential simulators investigated. Such a scenario consists of a generic salt repository for high-level nuclear waste, with in-drift emplacement of the waste packages and subsequent backfill of the drifts with crushed salt. The simulations performed include the stages of excavation, waste emplacement, backfilling and 100000 years of post-closure. Heat and also gas generation from the waste packages have been accounted for to investigate their effects on the barriers 
integrity. The comparison of the results obtained from the two simulators is very satisfactory, both in terms of the evolution of the natural salt barrier and the consolidation of the crushed salt backfill. Both rock salt and granular salt are characterized by strongly non-linear rheology, and their long-term evolution involves coupled thermal, hydraulic (multicomponent, multiphase) and mechanical processes that happen at different temporal and spatial scales. These features can be captured with the two simulators presented in this paper, using state-of-the-art knowledge. As more relevant information becomes available, the constitutive models and coupling functions used in the two simulators will be

updated, which will lead to improved numerical predictions. For the reference scenario of a high-level nuclear waste repository in a rock salt formation investigated in this research, the integrity of the geological barrier can be demonstrated due to the fact that the spatial extension of the infiltration zone is very well contained within the still tight (i.e., undisturbed) salt rock mass beyond this zone, and does not reach the overlying permeable formation even after 100000 years.

The satisfactory comparison of the results obtained not only provides a code-to-code verification, but also helps increase confidence and reliability on the numerical predictions. From the work performed, we conclude that the sequential approaches in TOUGH-FLAC and FLAC-TOUGH are able to numerically simulate the long-term coupled thermal-hydraulic-mechanical response of a generic salt repository for high-level nuclear waste.

\section{Acknowledgements}

Funding for this work has been provided by the Used Fuel Disposition Campaign, Office of Nuclear Energy of the U.S. Department of Energy, under Contract Number DE-AC02-05CH11231 with Lawrence Berkeley National Laboratory. Funding has also been provided by the German Federal Ministry of Education and Research (BMBF) under Contract Number 02S9082A. Internal review of a draft manuscript by James Houseworth (LBNL) is kindly acknowledged, as well as the constructive comments from two anonymous reviewers. 


\section{References}

[1] Hou Z. Mechanical and hydraulic behaviour of rock salt in the excavation disturbed zone around underground facilities. Int J Rock Mech Min Sci 2003;40:725-38. doi:10.1016/S1365-1609(03)00064-9. [2] Hunsche U, Hampel A. Rock salt - the mechanical properties of the host rock material for a radioactive waste repository. Eng Geol 1999;52:271-91. doi: 10.1016/S0013-7952(99)00011-3. [3] Stephansson O, Hudson J, Jing L. Coupled Thermo-Hydro- Mechanical-Chemical Processes in GeoSystems: Fundamentals, Modelling, Experiments, and Applications. Geo-Engineering Book Series, vol. 2. London: Elsevier; 2004.

[4] Tsang CF. Coupled hydromechanical-thermomechanical processes in rock fractures. Rev Geophys 1991;29(4):537-51.

[5] Wang W, Kosakowski G, Kolditz O. A parallel finite element scheme for thermo-hydro-mechanical (THM) coupled problems in porous media. Comput Geosci 2008;35:1631-41. doi: 10.1016/j.cageo.2008.07.007.

[6] Wolters R, Lux K-H, Düsterloh U. Evaluation of Rock Salt Barriers with Respect to Tightness: Influence of Thermomechanical Damage, Fluid Infiltration and Sealing/Healing. In: Proc $7^{\text {th }}$ Int Conf Mech Behav Salt (SaltMech7), Paris, 2012. p. 425-34.

[7] Tsang C-F, Stephansson O, Jing L, Kautsky F. DECOVALEX Project: from 1992 to 2007. Environ Geol 2009;57:1221-37. doi: 10.1007/s00254-008-1625-1.

[8] Kim J, Tchelepi HA, Juanes R. Stability, Accuracy and Efficiency of Sequential Methods for Coupled Flow and Geomechanics. SPE J 2009;119084.

[9] Olivella S, Carrera J, Gens A, Alonso E. Nonisothermal multiphase flow of brine and gas through saline media. Transp porous media 1994;15:271-93.

[10] Rutqvist J. Status of the TOUGH-FLAC simulator and recent applications related to coupled fluid flow and crustal deformations. Comput Geosci 2011;37(6):739-50. doi: 10.1016/j.cageo.2010.08.006. 
[11] Rutqvist J, Wu Y-S, Tsang C-F, Bodvarsson G. A Modeling Approach for Analysis of Coupled Multiphase Fluid Flow, Heat Transfer, and Deformation in Fractured Porous Rock, Int J Rock Mech Min Sci 2002;39(4):429-42. doi: 10.1016/S1365-1609(02)00022-9.

[12] Stone CM, Holland JF, Bean JE, Argüello JG. Coupled Thermal-Mechanical Analyses of a Generic Salt Repository for High-Level Waste. In: Proc $44^{\text {th }}$ US Rock Mech/Geomech Symp, Salt Lake City, 2010. Paper 10-180.

[13] Wang W, Kolditz O. Object-oriented finite element analysis of thermo- hydro-mechanical (THM) problems in porous media. Int J Numer Methods Eng 2007;69(1):162-01.

[14] Kim J. Sequential Methods for Coupled Geomechanics and Multiphase Flow. Ph.D. Dissertation, Stanford University; 2010.

[15] Jeannin L, Mainguy M, Masson R, Vidal-Gilbert S. Accelerating the convergence of coupled geomechanical-reservoir simulations. Int J Numer Anal Methods Geomech 2007;31(10):1163-81. doi: 10.1002/nag.576.

[16] Jha B, Juanes R. A locally conservative finite element framework for the simulation of coupled flow and reservoir geomechanics. Acta Geotech 2007;2(3):139-53. doi: 10.1007/s11440-007-0033-0.

[17] Settari A, Mourits F. A coupled reservoir and geomechanical simulation system. SPE J 1998;3(3):219-26. doi: 10.2118/50939-PA.

[18] Dean RH, Gai X, Stone CM, Minkoff SE. A comparison of techniques for coupling porous flow and geomechanics. SPE J 2006;11(1):132-40. doi: 10.2118/79709-PA.

[19] Felippa CA, Park KC. Staggered transient analysis procedures for coupled mechanical systems: formulation. Comput Methods Appl Mech Eng 1980;24(1):61-111. doi: 10.1016/0045-7825(80)90040-7. [20] Thomas LK, Chin LY, Pierson RG, Sylte JE. Coupled geomechanics and reservoir simulation. SPE J 2003;8(4):350-58. doi: 10.2118/87339-PA.

[21] Vijalapura PK, Strain J, Govindjee S. Fractional step methods for index-1 differential-algebraic equations. J Comput Phys 2005;203:305-20. doi: 10.1016/j.jcp.2004.08.015. 
[22] Popp T, Kern H, Schulze O. Evolution of dilatancy and permeability in rock salt during hydrostatic compaction and triaxial deformation. J Geophys Res 2001;106(B3):4061-78. doi:

10.1029/2000JB900381.

[23] Popp T, Minkley W, Salzer K, Schulze O. Gas transport properties of rock salt - synoptic review. In: Proc $7^{\text {th }}$ Int Conf Mech Behav Salt (SaltMech7), Paris, 2012. p. 139-48.

[24] Müller C, Lerch C, Otparlik K, Konietzky H. Simulation of the mechanical deterioration of rock salt at grain scale. In: Proc $7^{\text {th }}$ Int Conf Mech Behav Salt (SaltMech7), Paris, 2012. p. 105-12.

[25] Lux K-H, Rutenberg M, Seeska R, Düsterloh U. Kopplung der Softwarecodes FLAC ${ }^{3 \mathrm{D}}$ und TOUGH2 in Verbindung mit in situ-, laborativen und numerischen Untersuchungen zum thermischhydraulisch-mechanisch gekoppelten Verhalten von Tongestein unter Endlagerbedingungen. TU Clausthal, 2014. Final Rep BMWi-Proj 02E11041.

[26] Pruess K, Oldenburg C, Moridis G. TOUGH2 User's Guide, Version 2. Lawrence Berkeley National Laboratory, Berkeley, 2011. Rep LBNL-43134 (revised).

[27] Itasca. FLAC ${ }^{3 \mathrm{D}}$ (Fast Lagrangian Analysis of Continua in 3 Dimensions), Version 4.0. Itasca Consulting Group, Minneapolis; 2009.

[28] Hampel A, Argüello JG, Hansen FD, Günther RM, Salzer K, Minkley W et al. Benchmark Calculations of the Thermo-Mechanical Behavior of Rock Salt - Results from a US-German Joint Project. In: Proc $47^{\text {th }}$ US Rock Mech/Geomech Symp, San Francisco, 2013. Paper 13-456.

[29] Bechthold W, Rothfuchs T, Poley A, Ghoreychi M, Heusermann S, Gens A et al. Backfilling and Sealing of Underground Repositories for Radioactive Waste in Salt (BAMBUS Proj). Eur Atomic Energy Community, 1999. Rep EUR19124 EN.

[30] Hampel A, Günther RM, Salzer K, Minkley W, Pudewills A, Leuger B et al. Benchmarking of Geomechanical Constitutive Models for Rock Salt. In: Proc $44^{\text {th }}$ US Rock Mech/Geomech Symp, Salt Lake City, 2010. Paper 10-287. 
[31] Hampel A, Salzer K, Günther R-M, Minkley W, Pudewills A, Leuger B et al. Joint Projects on the Comparison of Constitutive Models for the Mechanical Behavior of Rock Salt - II. Overview of the models and results of 3-D benchmark calculations. In: Proc $7^{\text {th }}$ Int Conf Mech Behav Salt (SaltMech7), Paris, 2012. p. 227-36.

[32] Lowe MJS, Knowles NC. Further benchmark exercises to compare geomechanical computer codes for salt (COSA II Proj). Commission Eur Communities, 1989. Rep EUR12135 EN.

[33] Salzer K, Günther R-M, Minkley W, Popp T, Wiedemann M, Hampel A et al. Joint projects on the comparison of constitutive models - I. Overview of the projects, reference mine for 3-D benchmark calculations, in-situ measurements and laboratory tests. In: Proc $7^{\text {th }}$ Int Conf Mech Behav Salt (SaltMech7), Paris, 2012. p. 217-26.

[34] Carter JT, Hansen FD, Kehrman R, Hayes T. A Generic Salt Repository for Disposal of Waste from a Spent Nuclear Fuel Recycle Facility. Savannah River Natl Lab (Prep for US DOE), Aiken, 2011. Rep SRNL-RP-2011-00149 Rev 0.

[35] Hardin E, Voegele M. Alternative Concepts for Direct Disposal of Dual-Purpose Canisters. Prep for US DOE Used Fuel Disposition Campaign, 2013. Rep FCRD-UFD-2013-000102 Rev 0.

[36] Nutt M, Voegele M, Jove-Colon C, Wang Y, Howard R, Blink J et al. Used Fuel Disposition Campaign Disposal Research and Development Roadmap. Prep for US DOE Used Fuel Disposition Campaign, 2011. Rep FCR\&D-USED-2011-000065 Rev 0.

[37] Bechthold W, Smailos E, Heusermann S, Bollingerfehr W, Bazargan Sabet B, Rothfuchs T. Backfilling and Sealing of Underground Repositories for Radioactive Waste in Salt (BAMBUS II Proj). Eur Atomic Energy Community, 2004. Rep EUR20621 EN.

[38] Callahan GD, Mellegard KD, Hansen FD. Constitutive Behavior of Reconsolidating Crushed Salt. RE/SPEC Inc. (Prep for US DOE), Rapid City, 1998. Rep SAND-98-0179C. 
[39] Broome ST, Bauer SJ, Hansen FD. Reconsolidation of Crushed Salt to $250^{\circ} \mathrm{C}$ Under Hydrostatic and Shear Stress Conditions. In: Proc $48^{\text {th }}$ US Rock Mech/Geomech Symp, Minneapolis, 2014. Paper 147088.

[40] Kröhn KP, Zhang CL, Wolf J, Stührenberg D, Jobmann M, von Borstel L, Lerch C. The compaction behaviour of salt backfill at low porosities. In: Proc $7^{\text {th }}$ Int Conf Mech Behav Salt (SaltMech7), Paris, 2012. p. 155-62.

[41] Blanco Martín L, Rutqvist J, Birkholzer JT, Wolters R, Rutenberg M, Zhao J et al. Comparison of two modeling procedures to evaluate thermal-hydraulic-mechanical processes in a generic salt repository for high-level nuclear waste. In: Proc $48^{\text {th }}$ US Rock Mech/Geomech Symp, Minneapolis, 2014. Paper 147411.

[42] Kim J, Tchelepi HA, Juanes R. Stability and convergence of sequential methods for coupled flow and geomechanics: Fixed-stress and fixed-strain splits. Comput Methods Appl Mech Eng 2011;200(1316):1591-1606. doi: 10.1016/j.cma.2010.12.022.

[43] Mainguy M, Longuemare P. Coupling fluid flow and rock mechanics: formulations of the partial coupling between reservoir and geomechanics simulators. Oil Gas Sci Tech 2002;57:355-67.

[44] Rycroft CH. Voro++: a three-dimensional Voronoi cell library in C++. http://math.lbl.gov/voro++/(2009).

[45] Benz T. Small-strain stiffness of soils and its numerical consequences. Ph.D. Dissertation, University of Stuttgart; 2007.

[46] Hou Z. Geomechanische Planungskonzepte für Untertägige Tragwerke mit besonderer Berücksichtigung von Gefügeschädigung, Verheilung und hydromechanischer Kopplung, $1^{\text {st }}$ ed. Clausthal-Zellerfeld: Papierflieger; 2002.

[47] Kansy A. Einfluss des Biot-Parameters auf das hydraulische Verhalten von Steinsalz unter Berücksichtigung des Porendruckes. Ph.D. Dissertation, TU Clausthal; 2007.

[48] Coussy O. Poromechanics. Chichester: John Wiley \& Sons; 2004. 
[49] Peach CJ. Influence of deformation on the fluid transport properties of salt rocks. Ph.D. Dissertation, Utrecht University; 1991.

[50] Popp T, Kern H. Ultrasonic wave velocities, gas permeability and porosity in natural and granular rock salt. Phys Chem Earth 1998;23(3):373-78. doi: 10.1016/S0079-1946(98)00040-8.

[51] Schulze O, Popp T, Kern H. Development of damage and permeability in deforming rock salt. Eng Geol 2001;61:163-80. doi: 10.1016/S0013-7952(01)00051-5.

[52] Stormont JC. Gas permeability changes in rock salt during deformation. Ph.D. Dissertation, University of Arizona; 1990.

[53] Wolters R, Lux K-H, Düsterloh U. Evaluation of Rock Salt Barriers with Respect to Tightness: Influence of Thermomechanical Damage, Fluid Infiltration and Sealing/Healing. In: Proc $44^{\text {th }}$ US Rock Mech/Geomech Symp, Salt Lake City, 2010. Paper 10-215.

[54] Kenter CJ, Doig SJ, Rogaar HP, Fokker PA, Davies DR. Diffusion of brine through rock salt of roof caverns. In: Proc SMRI Fall Meet, Paris, 1990.

[55] Fokker PA. The behaviour of salt and salt caverns. Ph.D. Dissertation, Delft University of Technology; 1995.

[56] Carter JT, Luptak AJ, Gastelum J, Stockman C, Miller A. Fuel Cycle Potential Waste Inventory for Disposition. Prep for US DOE Used Nucl Fuel, 2011. Rep FCR\&D-USED-2010-000031 Rev 5.

[57] Suter D. Untersuchung der Gasbildungsmechanismen in einem Endlager für radioactive Abfälle und der damit verbundenen Auswirkungen auf die Führung des Nachweises der Endlagersicherheit. Bericht zur TA 1: Analyse der relevanten Gasbildungsmechanismen. Colenco Bericht, 2003.

[58] Hou Z, Lux K-H. Ein neues Stoffmodell für duktile Salzgesteine mit Einbeziehung von Gefügeschädigung und tertiärem Kriechen auf der Grundlage der Continuum-Damage-Mechanik. Geotechnik 1998;21(3):259-63.

[59] Hou Z, Lux K-H. A constitutive model for rock salt including structural damages as well as practiceoriented applications. In: Proc $5^{\text {th }}$ Conf Mech Behav Salt, Bucharest, 1999. p. 151-69. 
[60] Hou Z, Lux K-H. Ein Schädigungsmodell mit Kriechbruchkriterium für duktile Salzgesteine auf der Grundlage der Continuum- Damage-Mechanik. Bauing 2000;75(13):300-07.

[61] Hou Z, Lux K-H, Düsterloh U. Bruchkriterium und Fließmodell für ductile Salzgesteine bei kurzzeitiger Beanspruchung. Glueckauf-Forschungshefte 1998;59(2):59-67.

[62] Lux K-H. Gebirgsmechanischer Entwurf und Felderfahrung im Salzkavernenbau: Ein Beitrag zur Entwicklung von Prognosemodellen für den Hohlraumbau im duktilen Salzgebirge. $1^{\text {st }}$ ed. Stuttgart: Ferdinand Enke Verlag; 1984.

[63] Lerche S. Kriech- und Schädigungsprozesse im Salinargebirge bei mono- und multizyklischer Belastung. Ph.D. Dissertation, TU Clausthal; 2012.

[64] DBE. Numerische Untersuchungen zum Konvergenzverhalten eines Einzelhohlraumes. DBE Technology GmbH, 2001. Rep 22341011. 


\section{Figure captions}

Fig. 1. TOUGH-FLAC explicit sequential scheme (adapted from [11]). The highlighted zones correspond to the time step between time $t^{n}$ and $t^{n+1}$.

Fig. 2. FLAC-TOUGH explicit sequential scheme. The highlighted zones correspond to the time step between time $t^{n}$ and $t^{n+1}$.

Fig. 3. Mesh update in large strain mode. Example of initial and deformed discretizations in the (a) flow sub-problem and (b) geomechanics sub-problem. The initial mesh is represented by black lines.

Fig. 4. Geometry of the scenario investigated in the benchmark exercise, including an enlarged view of the drift area.

Fig. 5. Heat load per meter of drift for a waste package containing 10 PWR assemblies, assuming underground emplacement after 20 years of interim storage (after [56]).

Fig. 6. Evolution of dilatancy at the drift contour during the first 7 years of post-closure phase. Comparison between TOUGH-FLAC (top row) and FLAC-TOUGH (bottom row).

Fig. 7. Porosity evolution at three locations in the crushed salt, and also at one location in the rock salt at the drift sidewall. Lines correspond to TOUGH-FLAC and lines with points correspond to FLACTOUGH.

Fig. 8. Evolution of temperature at four different locations in the repository. Lines correspond to TOUGH-FLAC and lines with points correspond to FLAC-TOUGH.

Fig. 9. Evolution of pore pressure at three different locations in the repository. Lines correspond to TOUGH-FLAC and lines with points correspond to FLAC-TOUGH.

Fig. 10. Evolution of $\Delta P_{F l}$ as predicted by TOUGH-FLAC (top row) and FLAC-TOUGH (bottom row).

Fig. 11. Evolution of liquid saturation at the locations displayed in Fig. 9. Lines correspond to TOUGHFLAC and lines with points correspond to FLAC-TOUGH. 
Table 1. Mechanical and flow properties of the crushed salt, natural salt and confining layers.

\begin{tabular}{cccc}
\hline Property [unit] & Crushed salt & Rock salt & Confining layers \\
\hline Grain density, $\rho_{\text {grain }}\left[\mathrm{kg} \cdot \mathrm{m}^{-3}\right]$ & 2200 & 2200 & 2600 \\
Bulk modulus, $K[\mathrm{MPa}]$ & $150^{\mathrm{a}}$ & $16650^{\mathrm{b}}$ & 37900 \\
Shear modulus, $G[\mathrm{MPa}]$ & $70^{\mathrm{a}}$ & $7690^{\mathrm{b}}$ & 19500 \\
Linear thermal expansion coeff., $\alpha_{T}\left[\mathrm{~K}^{-1}\right]$ & $4 \cdot 10^{-5}$ & $4 \cdot 10^{-5}$ & $10^{-5}$ \\
Biot coefficient, $\alpha[-]$ & $1^{\mathrm{a}}$ & $0.003^{\mathrm{b}}$ & 1 \\
Relative permeability functions & Corey & Corey & $\begin{array}{c}\text { Van Genuchten } \\
\text { (liquid), Corey (gas) }\end{array}$ \\
Residual liquid saturation, $S_{l r}[-]$ & 0.05 & 0.05 & 0.02 \\
Residual gas saturation, $S_{g r}[-]$ & 0 & 0 & 0.01 \\
Van Genuchten's $\lambda[-]$ & N/A & N/A & 0.595 \\
\hline a $:$ non-constant value (reconsolidation); ${ }^{\mathrm{b}}$ : values are damage and healing dependent
\end{tabular}


Table 2. Initial flow parameters of the crushed salt, natural salt and confining layers.

\begin{tabular}{cccc}
\hline Parameter [unit] & Crushed salt & Rock salt & Confining layers \\
\hline Liquid saturation, $S_{l}[-]$ & 0.02 & 0.5 & 1 \\
Porosity, $\phi[-]$ & $30 \%$ & $0.2 \%$ & $12 \%$ \\
Permeability, $k\left[\mathrm{~m}^{2}\right]$ & $3 \cdot 10^{-13}$ & 0 & $10^{-17 \mathrm{a}}$ \\
Specific heat, $C\left[\mathrm{~J} \cdot \mathrm{kg}^{-1} \mathrm{~K}^{-1}\right]$ & 860 & 860 & $900^{\mathrm{a}}$ \\
Thermal conductivity, $\lambda\left[\mathrm{W} \cdot \mathrm{m}^{-1} \mathrm{~K}^{-1}\right]$ & 0.9 & 5 & $1.8^{\mathrm{a}}$ \\
\hline & ${ }^{\mathrm{a}}:$ constant values &
\end{tabular}

